\title{
Prevalence of Hypertension in relation to Overweight and Obesity among Non-teaching staff of College of Medicine, University of Ibadan, Oyo State
}

\author{
Article by Mercy Uchechi Ikechukwu-Orji \\ Texila American University, Guyana, South America \\ E-mail: mercy4good@gmail.com
}

\begin{abstract}
Hypertension and overweight/obesity prevalence are associated with high rates of morbidity and mortality which has become a vital public health concern worldwide. Among many studies conducted on hypertension prevalence, there is paucity of data on this subject among workers in the hospital environment. This study thus centered on determining the prevalence of hypertension among nonteaching staff of the College of Medicine, University of Ibadan (CoMUI).

A sum of 315 non-teaching staff of CoMUI on the University College Hospital premises participated in the survey. Blood Pressure (BP) was determined as specified in the ESH/WHO guidelines. BMI was assessed using a known-weight standardized weighing scale and heightometer. Data were analyzed using SPSS. Descriptive statistics, Chi-square and logistic regression were considered.

Hypertension prevalence among respondents was $25.4 \%$ (68.8\% male; $31.3 \%$ female). For the male respondents, the mean SBP was $132.2 \pm 19.0 \mathrm{mmHg}$ and it was significantly higher than that of the females $124.5 \pm 17.8 \mathrm{mmHg}(t=3.63, p<0.05)$. Also, the mean DBP of the male respondents $(86.04 \pm 11.19)$ was significantly higher than females $(80.95 \pm 11.62), t=3.92, p<0.05$. Prevalence of overweight and obesity was $33.1 \%$ and 20.3\%. Age group of 21-30 years and 31-40years are three times and two times less likely to develop hypertension than those within the age group of 51-60 years (O. $R=0.361(3 x)$ and $0.467(2 x)$; $95 \% C I=0.137-0.951$ and 0.219-0.995) see table 6.0.

Prevalence of 25.2\% indicated that one quarter of the non-teaching staffs of College of Medicine working within the University College Hospital are hypertensive. This suggests an urgent intervention to avoid resulting complications.
\end{abstract}

Keywords: Hypertension, Hypertension prevalence, Body Mass Index (BMI), Hospital environment, Obesity, Overweight.

\section{Introduction}

High blood pressure which is also known as hypertension results from environmental impacts acting over time on the genetically predisposed individual (Pickering, 1967). Hypertension is recognized as a silent killer, as it damages the target organs on a continuous and progressive basis until symptoms are manifested (Hoel and Howard, 1997). In adult, blood pressure is generally agreed to be high when the systolic pressure is equal to or greater than $140 \mathrm{mmHg}$ and diastolic pressure is equal to or greater than $95 \mathrm{mmHg}$ (World Health Organization/International Society of Hypertension,1999). The rate of Mortality and morbidity caused by hypertension on families and the society at large is so overwhelming. Apart from being a disease on its own, it is also a major risk However it remains inadequately managed everywhere (Godley, et al 2001). factor for stroke and heart diseases Hypertension is recognized as a silent killer due to the damages it causes on the target organs on a continuous and progressive basis until symptoms are manifested (Macmillian, Peto and Cutler, 1990). Population-based studies have shown that hypertension accounts for about $35 \%$ of all events relating to atherosclerotic, including $49 \%$ heart failure and related cases. It increases two- to three times in an individual risk of various cardiovascular consequences (Padwal, Strauss and McAlister, 2001).

There have been many studies and projections on hypertension prevalence and its related complications globally and in many nations of the world. It was calculated, chronic diseases contributed about $60 \%$ of the 56.5 million total reported deaths in the world in 2001 and roughly $46 \%$ 
of the burden of disease globally (World Health Organization, 2002). Also, it has been projected that chronic diseases will account for almost three-quarters of all deaths worldwide by 2020 and $75 \%$ of deaths from stroke, and $70 \%$ of deaths from diabetes will occur in developing countries (World Health Organization, 1998). Most of these chronic diseases have their roots on hypertension. Also, data from South Africa shows that the burden of non-communicable diseases, mostly cardiovascular diseases, including stroke, caused by hypertension, is greatly increasing among the urban Black African populace (Bradshaw, Groenewald et al, 2000). Worldwide, Hypertension is increasingly becoming a common health problem due to increase in longevity and prevalence of associated risk factors (Yusuf, et al 2001). In many developing countries particularly in urban societies, the current prevalence is already as high as those recorded in developed countries (Vorster, 2002). In 2002, hypertension was estimated to account for 13\% of deaths worldwide (WHO Report, 2002). The estimated total number of adults with hypertension in 2000 was 972 million. Of these, 333 million were estimated to be in economically developed countries and 639 million in economically developing countries. By 2025, the number of people with hypertension will increase by about $60 \%$ to a total of 1.56 billion as the proportion of elderly people will increase significantly (Kearney et al, 2005).

In Nigeria, a study conducted in 1997 estimated that over 4.3 million Nigerians above the age of 15years were hypertensive with systolic blood pressure of $160 \mathrm{mmHg}$ and above, and/or a diastolic of $95 \mathrm{mmHg}$ and above 5 . In 2010, another study estimated about 20.8 million cases of hypertension in Nigeria among people aged at least 20years with a prevalence of $28.0 \%$. It was also estimated that by 2030, the cases of hypertension among age 20years in Nigeria will increase to 39.1 million having prevalence of $30.8 \%$. Also, in Nigeria, the prevalence of hypertension ranged from $17-20 \%$ in the urban communities and $11.2 \%$ in the rural communities. A worksite study on prevalence of hypertension which was conducted among non-academic staffs in Obafemi Awolowo University, IleIfe, Nigeria, revealed a prevalence of $21 \%$ (Erhun, et al 2005).

Though the exact causes of hypertension are not usually known, a number of factors have been highly associated with the condition. These include: Smoking, obesity or being overweight, sedentary lifestyle, lack of physical activity, diabetics, high levels of salt intake (sodium sensitivity), Vitamin D deficiency, aging, Insufficient consumption of potassium, calcium, and magnesium, stress, high levels of alcohol consumption, high consumption of medicines including birth control pills, as well as family history of hypertension, , adrenal, chronic kidney diseases and thyroid problems or tumours (Mabuza, 2006).

However, a range of lifestyle changes has been shown in clinical trials to bring low blood pressure (Ebrahim and Smith, 1998) and to reduce the occurrence of hypertension (Stevens, et al 2001). These include loss of weight in overweight, physical activity (Hagberg, Park and Brown, 2000), reduced alcohol intake (Xin, et al, 2001), a diet rich in fresh fruits and vegetables as well as less of saturated fat food content and reduced dietary sodium intake (Sacks et al 2001).

It is quite clear that hypertension is a major public health problem in Sub-Saharan African countries, particularly in Nigeria. Levels of its detection treatment and control are very low and of great concern, suggesting that high levels of adverse effects including heart failure, stroke, and renal failure will become obvious in the years to come.

Due to the symptomless nature of hypertension, the proportion of people in any given population who are aware of their blood pressure is usually low not minding their locations ${ }^{10}$.

Sequel to this problem, this study was conducted to screen for hypertension as well as determine blood pressure pattern among hospital - based workers in Ibadan, Oyo State.

\section{Objectives of the study}

1. To determine the prevalence of hypertension among non-teaching staff of college of medicine Ibadan Oyo State

2. Determine prevalence of overweight/obesity among non-teaching staff of college of medicine Ibadan Oyo State

3. To determine the relationship between gender and prevalence of hypertension among nonteaching staff of college of medicine Ibadan Oyo State 
4. Determine the relationship between prevalence of hypertension and overweight/ obesity among non-teaching staff of college of medicine Ibadan Oyo State

\section{Methodology}

\section{Study area}

College of Medicine of the University College Hospital where this study was conducted is situated in Ibadan North Local Government Area of Oyo State, Nigeria. Being one of the pioneer institutions in Nigeria which was instituted on November $17^{\text {th }}, 1948$, the University existed originally as an independent external college of the University of London. College of Medicine as an arm of the University has 476 Non-Teaching Staff distributed within 44 departments. One of the departments is situated in Ibarapa community, 36 departments are located at the University College Hospital while 7 departments are at the main campus. The conduct of this study was limited to the non-teaching staff in the 36 departments located in College of Medicine.

\section{Study population}

The study population was comprised of non-teaching Staff in University College Hospital environment who are working in different department of the College of Medicine Ibadan.

\section{Sampling method}

The sampling method used for this study was purposive.

\section{Sample size}

Three hundred and fifteen (315) non-teaching staff was involved in the study being the total number of the entire staff of the College of Medicine, University College Hospital. As such, sample size calculation was not necessary.

\section{Study tools}

Semi-structured questionnaire was used after it was pretested among population with similar characteristics with the study population

\section{Collection of data}

The semi-structured questionnaires which was validated were self-administered with the help of two trained nurses who also helped in checking the blood pressure of the respondents.

\section{Measurement of blood pressure}

Measurement of blood pressure was done using Accoson mercury sphygmomanometer. The measurement was conducted in the staff respective offices. It began after the subject had rested for at least 5 minutes. The patients were seated in a comfortable chair with their backs supported and arms bared and supported at heart level. An appropriate adult cuff size was used to ensure accurate measurement. The cuff was inflated to $30 \mathrm{mmHg}$ above pulse occlusion. The systolic blood pressure was recorded at the first appearance of a sound and the diastolic blood pressure was recorded at the disappearance of the sound. Blood pressure was measured twice at two minutes intervals and if the readings differed by more than $5 \mathrm{mmHg}$, an additional reading was taken. Hypertension was diagnosed based on the laid down criteria by the World Health Organization -International Society for Hypertension (1999). A Patient was labelled hypertensive if an average of three readings showed the systolic blood pressure to be $140 \mathrm{mmHg}$ or greater and the diastolic blood pressure to be $90 \mathrm{mmHg}$ or greater (World Health Organization -International Society for Hypertension, 1999).

\section{Height measurement}

Respondents' height was measured with a measuring tape. Individual standing erects with the back against the wall and with the shoes removed. The measurement was recorded in meters to two decimal points. 


\section{Weight measurement}

Respondents' body weight was measured using simple bathroom scale which was standardized using a known weight. Placing the scale on a firm horizontal surface, the weight of each subject was measured with shoes removed and was recorded in kilometers to one decimal point. The pointer of the scale was adjusted to zero before and after each measurement to avoid error.

Table 1. Blood pressure measurement

\begin{tabular}{|l|l|l|}
\hline Categories & SBP $(\mathbf{m m H g})$ & $\mathbf{D B P}(\mathbf{m m H g})$ \\
\hline Optimal & $<120$ & $<80$ \\
\hline Normal & $<130$ & $<85$ \\
\hline High normal & $130-139$ & $85-89$ \\
\hline Mild (grade 1) & $140-159$ & $90-99$ \\
\hline Moderate (grade 2) & $160-179$ & $100-109$ \\
\hline Severe (grade 3) & $>180$ & $>110$ \\
\hline
\end{tabular}

Source: World health organization/ international society for hypertension (1999).

Data analysis: Analysis of the collated information followed the process of numbering of questionnaire, coding the information, data entering and analysing using Statistical Package for Social Sciences (SPSS) software. The differences were considered significant at $\mathrm{p}$ less than or equal to 0.05 . Multiple logistic regression analysis was used to check the correlates of hypertension.

\section{Results}

\section{Socio-demographic characteristics of the respondents}

Findings from the survey show that ages of respondents ranged from 20 to 60 years with a mean age of $42.8 \pm 13.2$ years. Majority 285 (90.5\%) of the respondents were of Yoruba ethnic group. Details are shown in Table 2.0 and figure 1.0.

Table 2. Education, marital status, religion and ethnic group

\begin{tabular}{|l|l|l|}
\hline Variable & Number & Percentage (\%) \\
\hline Sex & & \\
Male & 184 & 58.4 \\
Female & 131 & 41.6 \\
Total & $\mathbf{3 1 5}$ & $\mathbf{1 0 0 . 0}$ \\
\hline Educational Qualification & & \\
Primary education & 20 & 6.3 \\
Secondary education & 63 & 20.0 \\
Tertiary education & 232 & 73.7 \\
Total & $\mathbf{3 1 5}$ & $\mathbf{1 0 0 . 0}$ \\
\hline Marital status & & \\
Single & 58 & 18.4 \\
Married & 250 & 79.4 \\
Divorced & 2 & 0.6 \\
Widow/Widower & 5 & 1.6 \\
Total & $\mathbf{3 1 5}$ & $\mathbf{1 0 0 . 0}$ \\
& & \\
\hline Religion & & \\
Christianity & 266 & 84.4 \\
Islam & 49 & 15.6 \\
Total & $\mathbf{3 1 5}$ & $\mathbf{1 0 0 . 0}$ \\
\hline Administrative rank & 187 & \\
Senior & 28 & 59.48 .9 \\
Intermediate staff & 100 & 31.7 \\
Junior staff & $\mathbf{3 1 5}$ & $\mathbf{1 0 0 . 0}$ \\
\hline
\end{tabular}




\begin{tabular}{|l|l|l|}
\hline Total & & \\
\hline
\end{tabular}

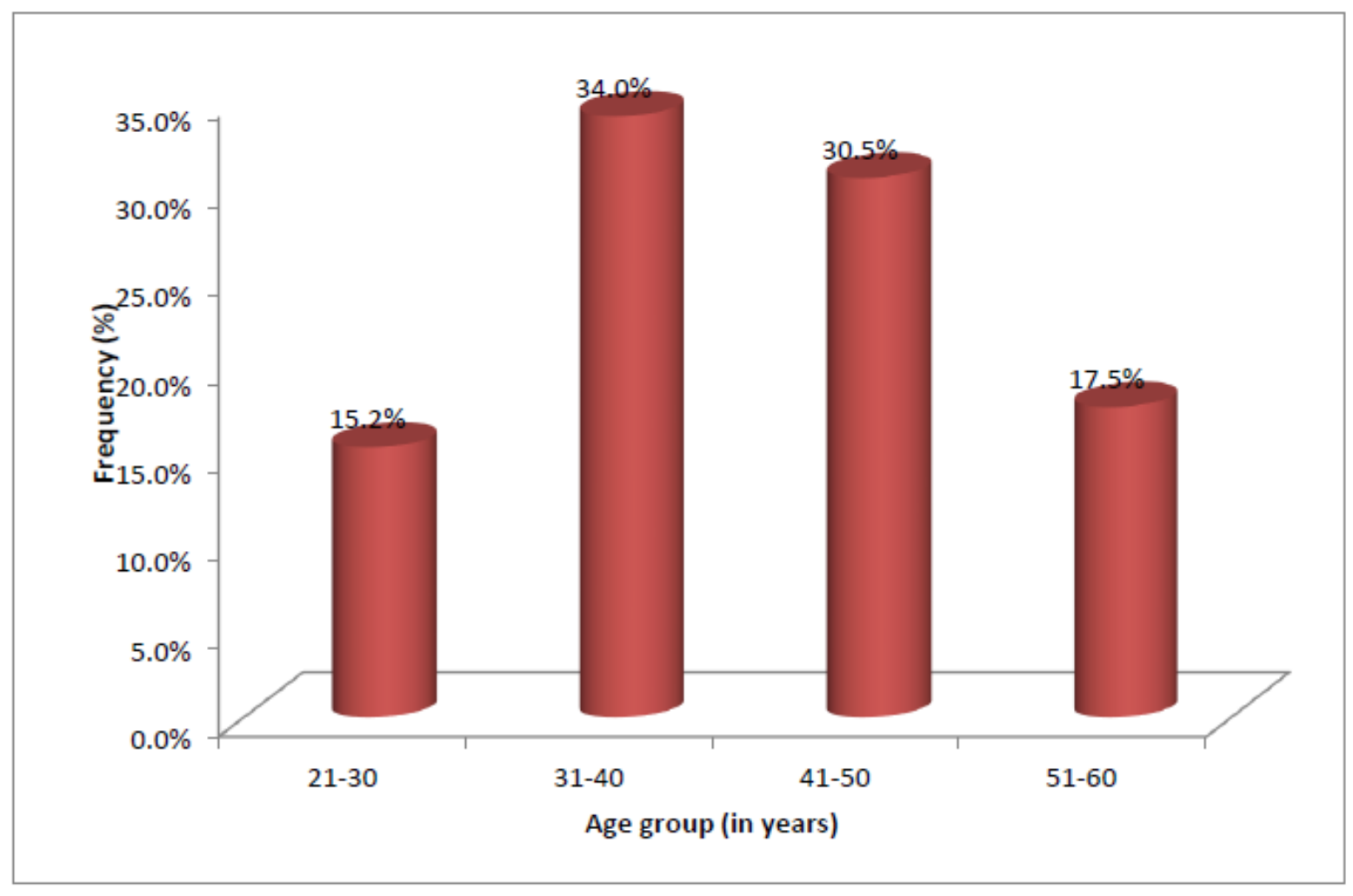

Figure 1. Age distribution of the respondents

\section{Prevalence of hypertension among the respondents}

The overall prevalence of hypertension was $25.4 \%$ (80/315) with grade $1 \mathrm{HT} 14.0 \%$, grade $2 \mathrm{HT}$ $9.5 \%$ and grade $3 \mathrm{HT} 1.9 \%$. The prevalence of hypertension across gender was $68.8 \%$ for male and $31.3 \%$ for female. Prevalence of hypertension steadily increased across different age groups with $6.5 \%$ for $21-30,28.6 \%$ for $31-40,37.7 \%$ for $41-50$ and $27.3 \%$ for $51-60$. Figure 2.0 shows the prevalence of hypertension.

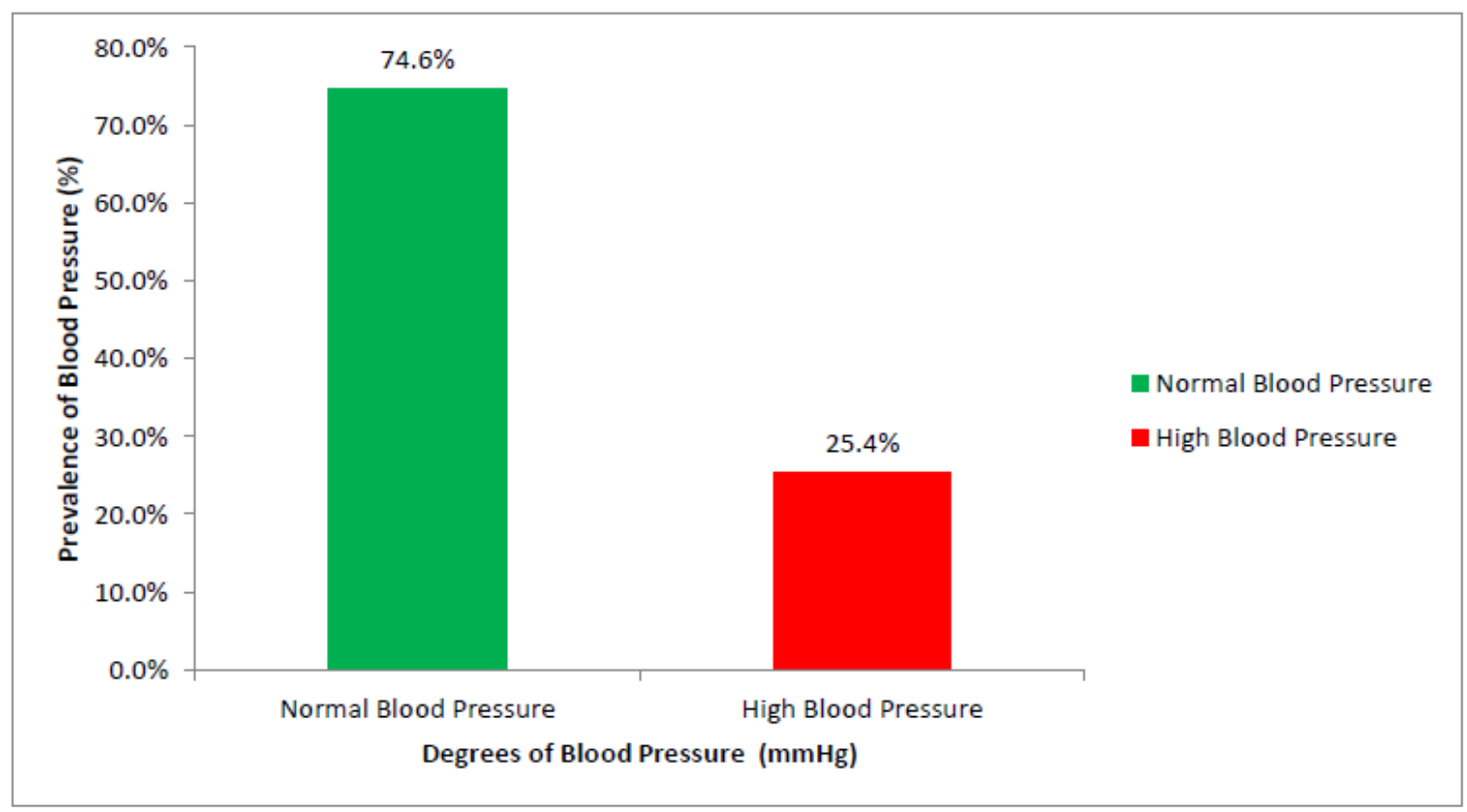

Figure 2. Prevalence of hypertension 


\section{Prevalence of overweight/ obesity among respondents}

Prevalence of overweight among respondents was found to be $33.1 \%$ of which $58.7 \%$ were male and $41.3 \%$ were female. Also $20.3 \%$ of the respondents were obese, out of which $26.6 \%$ were male and $73.5 \%$ were female). (See figure 3.0).

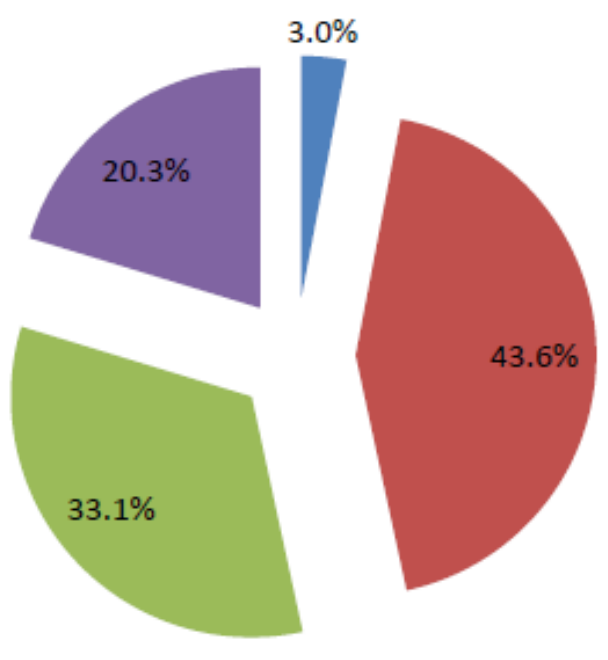

Undernurished

normal

Overweight

nobesed

Figure 3. Prevalence of overweight/obesity

\section{Relationship between gender, age and prevalence of hypertension}

The prevalence of hypertension among male respondents was found to be higher $(68.8 \%)$ than females $(31.3 \%)$. Also, hypertension prevalence among age group $41-50$ years was highest $(37.7 \%)$ compared to all other age groups. Details are shown in figures 4 and 5.

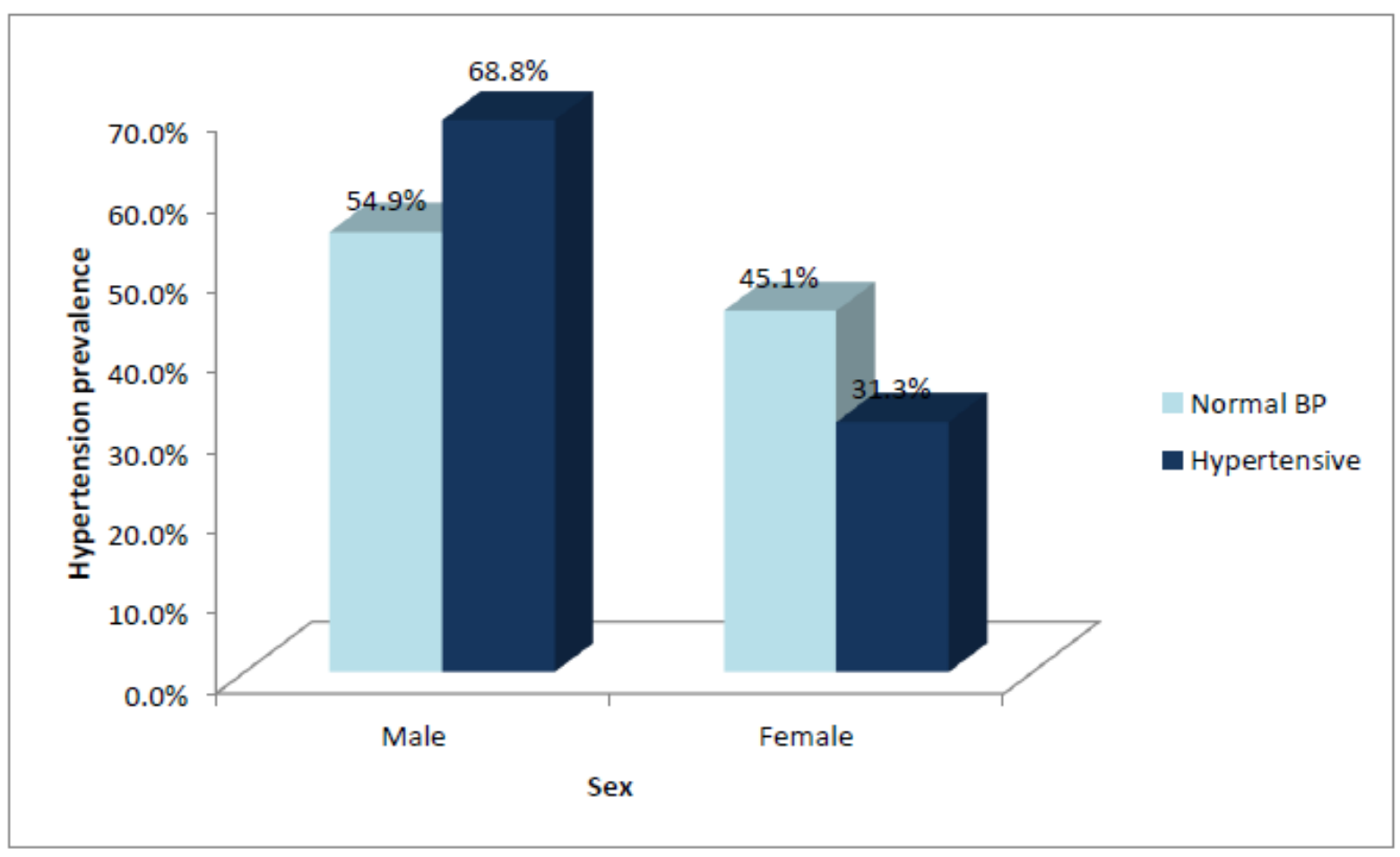

Figure 3. Prevalence of hypertension among participants by sex

$\mathrm{X} 2=4.717$

$\mathrm{P}$-value $=0.030$ 


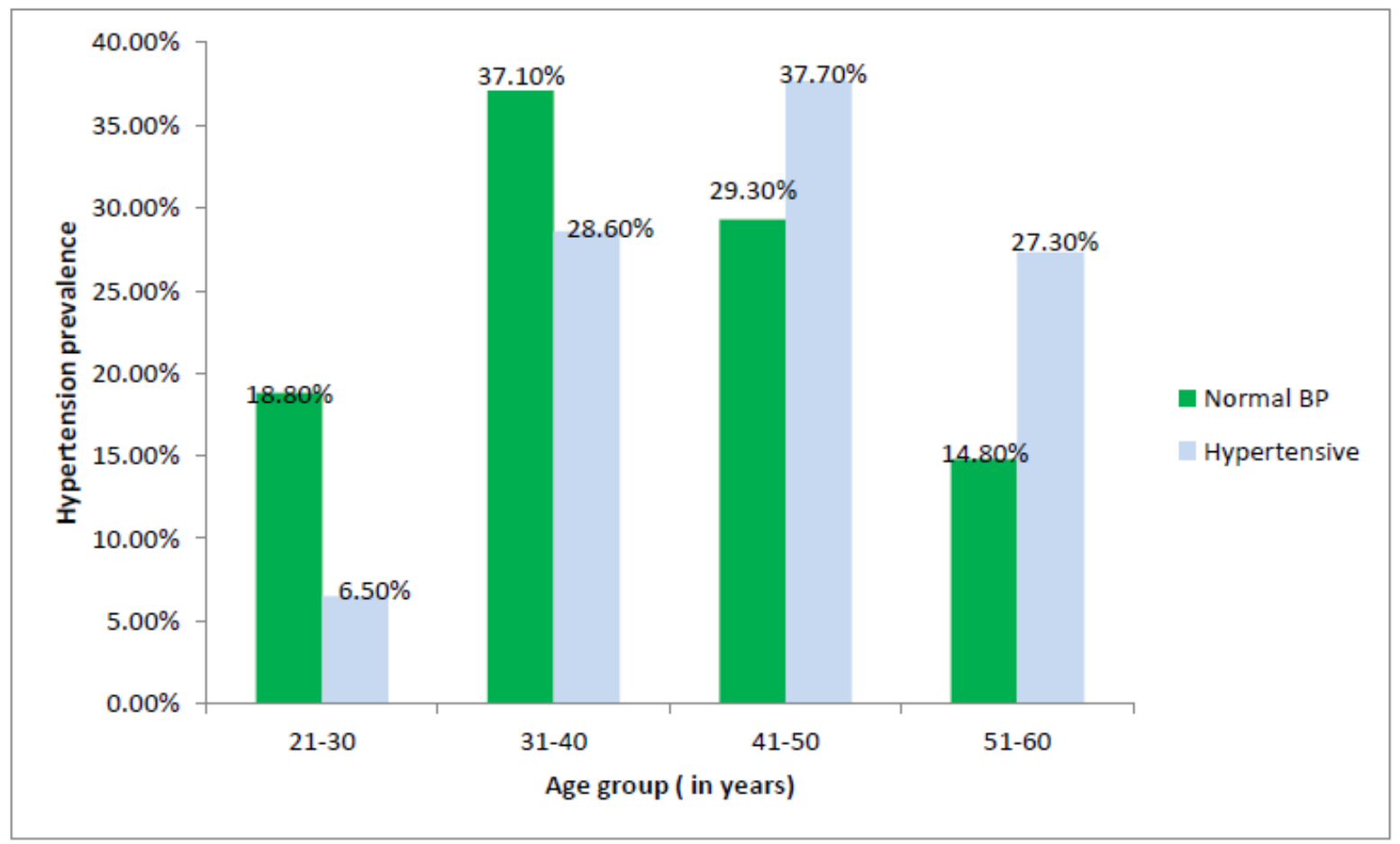

Figure 4. Prevalence of hypertension among participants by age

$\mathrm{X} 2=0.005$

$\mathrm{P}$-value $=12.994$

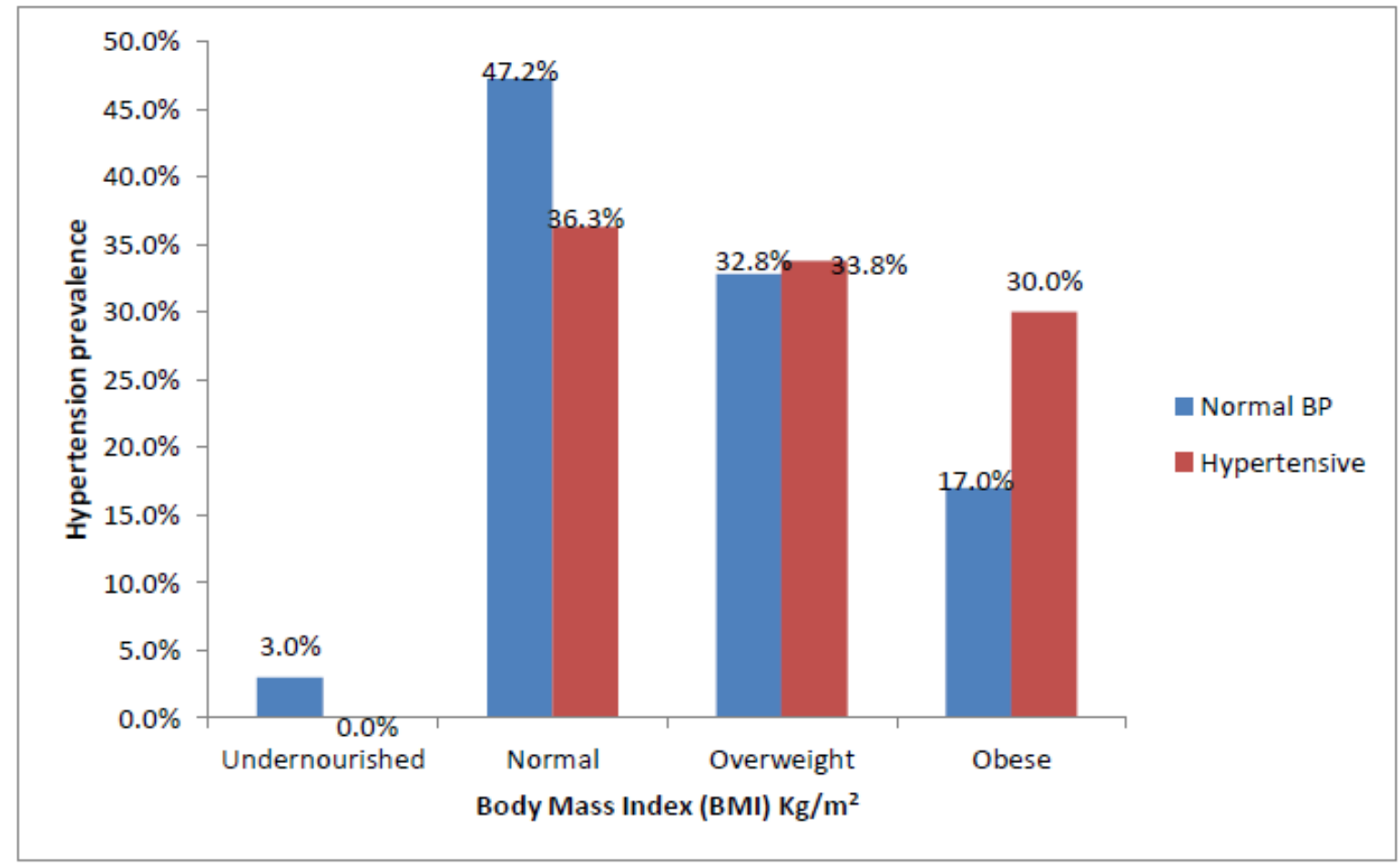

Figure 5. Prevalence of hypertension among participants by BMI

The result of the multiple regression showed that age, body mass index (BMI) and sex are correlates of hypertension. Respondents within the age group of 21-30 years and 31-40years are three times and two times less likely to develop hypertension than those within the age group of 51-60 years $(\mathrm{O} . \mathrm{R}=0.361(3 \mathrm{x})$ and $0.467(2 \mathrm{x}) ; 95 \% \mathrm{CI}=0.137-0.951$ and $0.219-0.995)$ see table 3.0. 
Table 3. Multiple regression analysis

\begin{tabular}{|l|l|l|l|}
\hline Variables & Odds ratio & 95\% CI & P-value \\
\hline Age group & & & \\
\hline $21-30$ & 0.361 & $0.137-0.951$ & 0.039 \\
\hline $31-40$ & 0.467 & $0.219-0.995$ & 0.048 \\
\hline $41-50$ & 0.771 & $0.375-1.585$ & 0.479 \\
\hline $51-60^{*}$ & & & \\
\hline BMI & & & \\
\hline Undernourished & 0.000 & 0.000 & 0.999 \\
\hline Normal & 0.290 & $0.135-0.624$ & 0.002 \\
\hline Overweight & 0.370 & $0.175-0.782$ & 0.009 \\
\hline Obese & & & \\
\hline Sex & & & \\
\hline Male & 0.400 & $0.211-0.756$ & 0.005 \\
\hline Female & & & \\
\hline
\end{tabular}

\section{Discussion}

\section{Prevalence of hypertension}

Prevalence of hypertension was found to be $25.2 \%$ thus one quarter of the non-teaching staff of College of Medicine who is working within the University College Hospital are hypertensive. This is similar to the findings of Mohan, Deepa, Farooq, Prabhakaran and Reddy, (2010) and findings of the World Health Organization (WHO) and Indian Council of Medical Research (ICMR) on noncommunicable disease (NCD) risk factor surveillance where the prevalence of hypertension among the industrial population was $26 \%$ in all ten centres in India and $25.4 \%$ in Chennai. Their findings suggest that hypertension is more obvious in workplace than in the general community given the prevalence of 8-10\% reported by Akinkugbe (1992) in rural communities in Africa, the prevalence of $5.9 \%$ reported by Oviasu (1978) in a rural community in mid-western Nigeria and $11.0 \%$ reported by Kuti (1993) in Aiyetoro community (also rural) in Ondo state.

The prevalence of hypertension among the respondents was seen to be higher in males $(68.8 \%)$ than in females $(33.1 \%)$. This is in line with the study conducted by Omuemu, Okojie and Omuemu (2006) where the prevalence of hypertension was higher in males than in females (24.8\% male; $13.2 \%$ female). Also, study on the systematic review of hypertension in Sub-Saharan African by Juliet, Liam and David (2007) reported a higher prevalence in males than in females (21.6\% male; $12.5 \%$ female). The lower prevalence of hypertension observed in women could be attributed to the hormonal factor. Research has shown that oestrogen which is females' hormone has a regulatory effect on hypertension (Radwanska, 1993).

\section{Prevalence of overweight/obesity}

It is quite glaring that prevalence of overweight and obesity are significantly high among the nonteaching staff of college of medicine. Furthermore prevalence of obesity was higher in female than in male which might have been resulted from sedentary life style typically associated with women. The higher prevalence in female could also have contributed to the low prevalence of hypertension in female than in male because sex hormone binding globulin concentration is lower in obese women thus increasing the amount of bio available oestrogen (Ewa Radwanska, 1993).

\section{Relationship between age, gender, overweight/obesity and prevalence of hypertension}

Prevalence of hypertension is seen to increase with age. It was also observed that the prevalence of hypertension increased with age which is in agreement with reports from several studies (Annlia et al, 1988). This was expected since blood pressure tends to increase with advancing age due to hardening of the arteries. This trend of increasing blood pressure with age could also be a reflection of increasing risk factors for hypertension such as obesity which also increases with age (Okojie et al, 2000). 
The prevalence of hypertension among the respondents was seen to be higher in male $(68.8 \%)$ than in female (33.1\%). This is in line with the study conducted by Omuemu, Okojie and Omuemu (2006) where the prevalence of hypertension was higher in male than in female (24.8\% male; $13.2 \%$ female). Also, study on the systematic review of hypertension in Sub-Saharan African by Juliet, Liam and David (2007) reported a higher prevalence in male than in female (21.6\% male; $12.5 \%$ female). The lower prevalence of hypertension observed in women could be attributed to the hormonal factor. Research has shown that oestrogen which female hormone has a regulatory effect on hypertension (Radwanska, 1993).

The study also showed that there is significant relationship between BMI and hypertension. A BMI of 25 correlates closely with increased blood pressure (Abdul-Rahim, Abu-Rmeilehnu, Husseini, Holmboe, Sen, Jarvell and Bjertness, 2000). Other studies also support the fact that weight gain is associated with increased blood pressure and increased incidence of hypertension (Mertens and Van Gaal, 2000). In general, being overweight is associated with a two to six-fold increase in the risk of developing hypertension (Dickey and Janick, 2001). Clinical trials have proved that weight loss is effective in the primary prevention of hypertension as well as in the reduction of both systolic and diastolic blood pressure in patients with normal and high blood pressure (Dickey and Janick, 2001). Several epidemiological studies have shown an association between BMI and blood pressure in normal and overweight patients. Weight loss has been recommended for the obese hypertensive patient and has been shown to be the most effective non-pharmacological treatment approach (Patel, 2000).

\section{Conclusion}

This study has once again highlighted the fact that hypertension is a problem in our society, even in the health environment. This is seen in the prevalence of hypertension among them whereby one out of every four non-teaching staff is hypertensive. Also, overweight and obesity has been significantly proven as one of the risk factors of hypertension. It is quite disheartening that those considered being more prone to receiving health information and practicing such by virtue of their work environment as well as looming consequences rampant in the hospital where they work are at high risk of this menace called hypertension. This leaves a question in the heart of many that, if the prevalence of hypertension, overweight and obesity are high among people in learning and hospital environment, what is likely going to be the prevalence among rural communities where there is little or no health information of such? This calls for public health action to help workers of this category live up to expectation health wise.

\section{Recommendations}

To address the findings of this research, the following recommendations should be considered.

1. Periodic departmental hypertension screening should be included in the hospital policy to help the staff working in the hospital environment

2. Live presentations of consequences and complications of overweight, obesity and hypertension should be conducted monthly among the staff as a reinforcing factor for practicing healthy living.

3. Sports/ recreational programme should be part of work schedule for staff working in the hospital environment.

\section{References}

[1]. Abdul-Rahim HF, Abu-Rmeilehnu NM, Husseini A, Holmboe OH, Sen G, Jarvell J and Bjertness E. (2002). Obesity and selected co-morbidities in an urban Palestinian population. Int $J$ Obes Relat Metab Disord; 269:58-64.

[2]. Akinkugbe $\mathrm{OO}(\mathrm{Ed})$. Non-communicable diseases in Nigeria, Series 1. Federal Ministry of Health and Human Services, Lagos. 1992;1-12.

[3]. Bradshaw D, Groenewald P, Laubscher R, Nannan P, Nojilana P, Norman R, Pieterse D and Schneider M (2000) Initial burden of disease estimates for South Africa. South African Medical Research Council. Available at: http://www.mrc.ac.za/bod/bod.htm.

[4]. Dickey RA, Janick JJ. (2001). Lifestyle modifications in the prevention and treatment

[5]. of hypertension. Endocrine Practice; 7:392-399. 
[6]. EbrahimS.and Smith GD, (1998) Lowering blood pressure. A systematic review of sustained effect of non-pharmacological interventions. J public Health Med; 20:4441-4448.

[7]. Erhun W. O, Olayiwola, G Agbani, E. O and Omotoso, N. S (2005) Prevalence of Hypertension in a University Community in South West Nigeria; Africa Journal of Biomedical Research (8); 1519.

[8]. Ewa Radwanska (1993). The role of reproductive hormones in vascular disease and hypertension. Section of Reproductive Endocrinology and Infertility, Department of Obstetrics and Gynaecology. Steroids Volume 58, Issue 12, Pages 605-610.

[9]. Godley P, Pham H, Woodward B, Yokoyama K, Maue S.K. (2001) opportunities for improving the quality of hypertension care in a managed care setting, Am J Health Syst Pharm.

[10].Hoel D, Howard RB. Hypertension-stalking the killer. Postgrad MedJ 1997;101:1 16-121.

[11].Hagberg JM, Park JJ and Brown MD, (2000) the role of exercise training in the treatment of hypertension: an update. Sports Med; 30:193-206.

[12].Juliet Addo, Liam Smeeth and David A. Leon (2007) Global Health-Hypertension in SubSaharan. Africa. Hypertension in Sub-Saharan Africa; a Systematic Review From the Department of Epidemiology and Population Health, London School of Hygiene and Tropical Medicine, Keppel Street, London, UK.

[13].Kearney PM et al. Global burden of hypertension: analysis of worldwide data. Lancet 2005 Jan 15-21; 365(9455): 217-23.

[14].Kuti JA. (1993). Pattern of blood pressure and prevalence of hypertension in a special rural Nigerian community. Niger. Med. J; 25(3): 104-6.

[15].Mabuza, LH. (2006). Hypertension. The South African Journal of CPD 24(5): 230-231

[16].Macmillian S, Peto R and Cutler J (1990). Blood pressure, stroke and coronary heart disease, part 1. Prolonged differences in blood pressure: prospective observational studies corrected for the regression dilutional bias. Lancet,335:765-774s.

[17].Mertens IL. and Van Gaal LF. (2000). Overweight, obesity, and blood pressure: the effects of modest weight reduction. Obesity Research; 8:270-278.

[18].Mohan V, Deepa M, Farooq S, Prabhakaran D, Reddy KS. (2010). Surveillance for cardiovascular disease risk factors among the south Indian Industrial population. a developing country. Public Health; 114:273-75.

[19]. Oviasu VO. (1978). Arterial blood pressure and hypertension in a rural Nigerian community. Afr. J Med Sci; 7: 137-143.

[20].Omuemu VO, Okojie OH and Omuemu CE JMBR: (2006). Blood pressure pattern and prevalence of hypertension in a rural community in Edo State. A Peer-review Journal of Biomedical Sciences. Vol. 5 No.2 pp-79-86.

[21].Okojie OH, Isah EC and Okoro E. (2000). Assessment of health of senior executives in a developing country. Public Health; 114:273-75.

[22].Padwal R, Strauss SF, McAlister FA. (2001). Cardiovascular risk factors and their effects on the decision to treat hypertension. Evidence-based review. BMJ; 322:977-980.

[23].Patel JC. (2000). Obesity effective and safe management. Indian J Med Sci 2000; 54:499-507

[24].Pickering (1967). The inheritance of arterial pressure. Epidemiology of hypertension, Edited by J. Stamler, R. Stamler, and T. Pullman.Grune and Stratton: New Yorkp.18.

[25].Sacks FM, Svetkey LP, Vollmer WM, AppelLJ, Bray G A and Harsha D, (2001). Effects on blood pressure of reduces dietary sodium and the Dietary Approach to Stop Hypertension (DASH) diet. DASH sodium collaborative research Group. N. Engl J Med. 344:3-10.

[26].Vorster, H.H (2002). The emergence of cardiovascular disease during urbanization of Africans. Public Health Nutr; 5:239-243.

[27].World Health Organization/International Society of Hypertension Guidelines for the management of hypertension. J Hypertension, 1999; 17: 151-83.

[28].World Health Organization. The world health report 2002. Geneva, Switz: World Health Organization; 2002.

[29].World Health Organization, (1998). The world health report 1998. Life in the 21st century: a vision for all. Geneva, Xin X, He J, Frontini M.G, Ogden L.G, Motsamai O.I and Whelton P.K, 
Texila International Journal of Public Health

Special Edition Apr 2019

(2001). Effect of alcohol reduction on blood pressure. A meta-analysis of randomized controlled trial. Hypertension.38:1112-1117.

[30].Yusuf, Reddy, Ounpuu and Anand, (2001) Global burden of Cardiovascular diseases, part 1: General considerations, the epidemiologic transition, risk factors and impact of urbanization; 104:2746-2753. 